\title{
Aquitano y Vascónico
}

\section{Aquitanian and Vasconic}

\author{
Joaquín Gorrochategui Churruca \\ Instituto de Ciencias de la Antigüedad, UPV/EHU \\ joaquin.gorrochategui@ehu.eus
}

Resumen: En este trabajo se da cuenta de la situación lingüística de Aquitania y Vasconia en la antigüedad. La documentación conservada, de naturaleza onomástica, prueba la existencia de una lengua o de variedades lingüísticas relacionadas estrechamente con la lengua vasca. Se discuten las características específicas de la documentación y los problemas textuales y metodológicos a la hora de su descripción, análisis y explicación lingüística.

Palabras clave: Aquitano. Lengua vasca. Onomástica. Epigrafía paleohispánica.

Abstract: This work deals with the linguistic situation of Aquitaine and Vasconia in Antiquity. The preserved documentation, of an onomastic nature, proves the existence of a language or linguistic varieties closely related to the Basque language. The specific characteristics of the documentation and the textual and methodological problems are discussed at the same time of its description, analysis and linguistic explanation.

Key words: Aquitanian. Basque language. Onomastics. Palaeohispanic epigraphy.

Recepción: 16.08.2020 | Aceptación: 01.09.2020

Financiación: Este trabajo se ha realizado en el marco del proyecto MINECO FFI201236069-C03-01 y del Grupo de Investigación del Gobierno Vasco IT1344. 


\subsection{Introducción}

El vascónico y el aquitano son dos variedades lingüísticas regionales, documentadas en la antigüedad mediante material onomástico en territorio vascón y aquitano respectivamente y que por razones geográficas, históricas y sobre todo lingüísticas constituyen las fases previas de la lengua vasca. En este sentido, la lengua vasca presenta una situación antagónica a la del resto de las lenguas paleohispánicas conocidas, ya que mientras estas, tras haber dejado un número mayor o menor de textos epigráficos como testimonio de sí mismas, se extinguieron bajo la presión latina, la lengua vasca que logró sobrevivir a la extinción de todas las lenguas mediterráneas y muchas europeas ante la romanización o germanización posterior no dejó, sin embargo, textos epigráficos en la antigüedad. Se parece en ello a otras dos zonas europeas, con más parecido con la britónica que con la ilírica. A pesar de la fuerte romanización de la zona meridional de Britania y de la posterior germanización, tanto el galés como el córnico, ya extinto, son continuadores del celta britónico hablado en la isla antes de la llegada de los romanos. Dicha variedad lingüística se conoce solamente a través de material onomástico y quizá dos inscripciones procedentes del santuario de Bath, cuya procedencia gala no está excluida (Mullen 2007). Es una situación muy parecida a la vascónica-aquitana, conocida solamente por leyendas monetales, nombres de persona y de divinidad trasmitidos por epígrafes latinos, a los que se añaden unos topónimos obtenidos de las fuentes greco-latinas. De los escasos textos epigráficos hallados en su territorio, unos son claramente foráneos y otros no pueden ser adscritos inequívocamente a una variedad lingüística vasca. De igual modo, el hecho de que sobre el territorio denominado ilirio en la antigüedad se documentan a partir del s. XI las primeras menciones a la lengua albanesa, seguidas algo más tarde de material onomástico, glosas y cortos textos, constituye un paralelo de la situación histórica ocurrida en territorio vasco, donde también se produce un largo periodo oscuro entre la antigüedad y los primeros testimonios medievales. A diferencia del caso vasco, sin embargo, donde las relaciones lingüísticas entre el vascónico y aquitano por un lado y la lengua vasca histórica, por otro, son incontrovertibles, la relación entre el ilírico y el albanés carece de pruebas totalmente inequívocas, aunque sea una hipótesis plausible (Katičić 1980, 115).

Denominamos aquitano a la lengua autóctona de Aquitania, según el testimonio de César en el momento de la conquista de las Galias y de Estrabón en época de Augusto. Ambos autores mencionan explícitamente la particu- 
laridad étnica de los aquitanos, que según César se diferencian de los galos y de los belgas por su lengua, instituciones y leyes (Hi omnes lingua, institutis, legibus inter se differunt, $B G$ 1.1). Estrabón 4.1 amplía la noticia, aduciendo un parecido mayor de los aquitanos con los iberos no solo en lengua, sino también en aspecto físico. Ambos autores también coinciden en señalar que los límites geográficos de Aquitania vienen dados por los montes Pirineos al sur, el curso del río Garona por el este y el norte, y el Océano Atlántico por el oeste, configurando lo que ha venido en llamarse el "triángulo aquitano". Estrabón nos informa de que Augusto, en su remodelación de las provincias del imperio hacia el año 15 a. C., añadió a la Aquitania primitiva catorce tribus galas entre el Garona y el Loira, de modo que el nombre primitivo se aplicó en el alto imperio a una zona muy extensa, mayormente de lengua gala. La remodelación de Diocleciano en la última década del s. III devolvió a la antigua Aquitania cesariana su estatus de provincia bajo la denominación de Novempopulania, decisión administrativa a la que se refiere una singular inscripción votiva hallada en Hasparren (Pirineos Atlánticos) en época renacentista (CIL XIII, 412).

Con el término vascónico nos referimos a la lengua indígena de los vascones, pueblo hispano localizado en el territorio correspondiente a Navarra y a zonas vecinas, a partir de la identificación como vasconas de las ciudades de este territorio en las fuentes clásicas. Los vascones son mencionados por primera vez por Salustio en referencia a los sucesos de la guerra sertoriana (entre el 82 y 72 a. C.). Tras la inclusión del territorio en la organización imperial romana, vertebrada políticamente en torno a las ciuitates, el étnico cayó en desuso, quedando limitado su empleo durante el alto imperio a la denominación de algunas unidades militares ubicadas en lugares fronterizos del imperio, como en Britania o Germania. El término vuelve a aparecer en fuentes literarias del s. IV d. C. - en algún poema de Prudencio o en la correspondencia entre Ausonio y Paulino de Nola-, en las que se caracteriza a los vascones como pueblo "feroz" e incivilizado, visión que pasará a las fuentes posteriores merovingias y visigodas de los ss. VI y VII, en las que el término posee ya un fuerte contenido étnico y político. Las cartas latinas medievales usan el adverbio vasconice para referirse a testimonios "en lengua vasca", en oposición a romanice, que hace referencia a enunciados "en lengua romance". De la primera proviene vascuence, la palabra española tradicional para de- 
signar la lengua vasca. Con el término vascónico (inglés Vasconic) ${ }^{1}$ queremos identificar la lengua de los antiguos vascones, diferenciándola del vascuence o vasco histórico (Basque), cuyos testimonios se documentan desde la Edad Media hasta el presente sin solución de continuidad.

Tanto el aquitano como el vascónico presentan unas estrechas y exclusivas relaciones lingüísticas con la lengua vasca histórica, de modo que no hay duda en clasificarlas como lenguas o variedades pertenecientes a la misma familia. Más adelante se discutirá sobre la naturaleza de dichas relaciones. Por otro lado, es ampliamente aceptada la idea de que la lengua vasca es una lengua aislada desde el punto de vista genético, sin parentesco probado con ninguna otra lengua del mundo, a pesar de los numerosos intentos habidos en los dos últimos siglos por relacionarla con diferentes lenguas y familias. Entre los ensayos comparativos siempre han destacado aquellos que se esforzaban por hallar relaciones entre el vasco y el ibérico, la lengua no-indoeuropea con más abundante documentación epigráfica de la Hispania prerromana, en razón tanto de la cercanía geográfica como de ciertas similitudes tipológicas. No cabe duda de que la tarea comparativa entre el vasco y el ibérico o entre el vascónico-aquitano y el ibérico se enfrenta a problemas graves, debido al hecho de que en el primer caso la lengua ibérica no está descifrada y en el segundo comparamos elementos onomásticos cuyo parecido superficial no garantiza la identidad de sentidos ni su condición de cognados. Pero aun en estas condiciones, no hallamos en los textos ibéricos morfemas nominales, pronominales o verbales que puedan identificarse en forma y función con posibles correlatos vascos, de modo que la lengua vasca ha resultado de nulo o escaso valor para avanzar en la comprensión del ibérico, a diferencia de lo que ha ocurrido en el campo celtibérico, cuyas inscripciones han recibido aclaración a partir de la comparación con otras lenguas célticas y de la gramática indoeuropea.

\subsection{La documentación epigráfica y onomástica}

Como ni en Aquitania ni en Vasconia contamos con inscripciones inequívocamente atribuibles a variedades antiguas de la lengua vasca, carecemos de un área epigráfica bien delimitada, que sea el reflejo mínimo y seguro de la extensión de la lengua. Tenemos que valernos del negativo de un área epigráfica, es decir de aquel territorio vacío de inscripciones indígenas en el

1 Nos diferenciamos también del sentido dado al término por Theo Venneman en sus trabajos, que lo usa para referirse a la antigua lengua paleo-europea responsable de buena parte de la toponimia e hidronimia europeas tras el último periodo glacial. 
que no entran de modo sistemático inscripciones atribuibles a otras lenguas vecinas. Este vacío epigráfico se aprecia claramente en Aquitania, cuyo territorio está libre de inscripciones galas que se localizan siempre al otro lado del Garona (entre los Bituriges Vivisci o los Nitiobroges, p. ej.) ${ }^{2}$ y de inscripciones ibéricas, que se limitan a la zona costera de la Narbonense, a las rupestres de la Cerdaña y al enclave interior de Vieille Toulouse. ${ }^{3}$ Los únicos epígrafes indígenas de Aquitania son un par de fragmentos de una phiale o pátera argéntea (BDH LAN.01) procedentes de una tumba principesca de Vieille Aubagnan (Landes), que la investigación arqueológica y filológica reciente ha identificado como productos suntuarios de origen ibérico, manufacturados e inscritos en el Levante hispano.

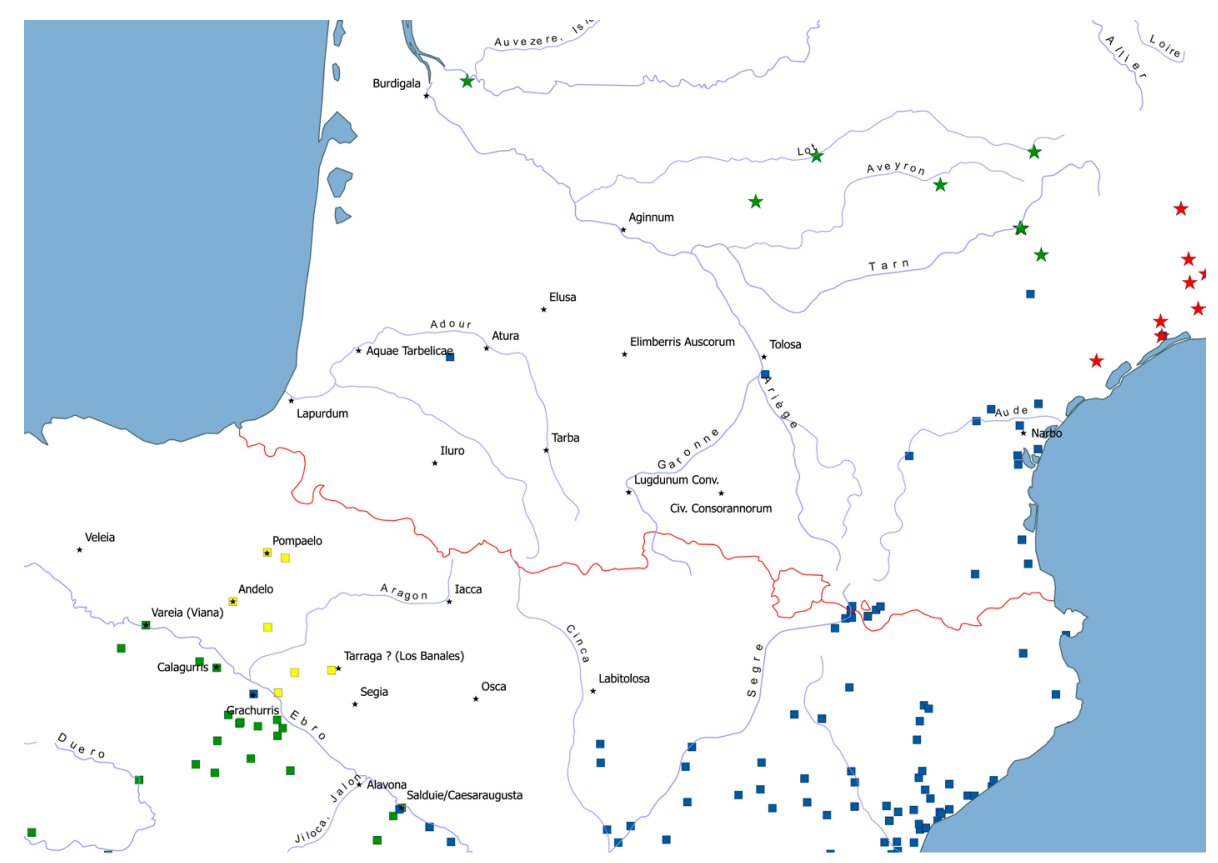

Mapa. 1. Inscripciones indígenas en el territorio vascónico-aquitano y zonas limítrofes.

2 De Vayres (Gironde), territorio de los Bituriges Vivisci, procede un óstracon con cuentas de alfarero (RIG II.2.L-27) y a los Nitiobroges pertenecía un torque de oro con la

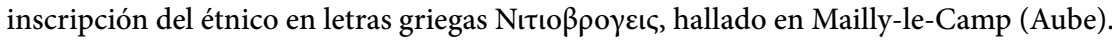

3 Mientras que las inscripciones ibéricas de la costa narbonense, entre Ensérune y Perpignan, algunas de ellas remontables a fines del s. V a. C., son parte nuclear del territorio ibérico (BDH zona B), las inscripciones de Vieille-Toulouse, pintadas sobre ánforas itálicas (BDH HGA.01), son testimonio de la incursión del comercio itálico hacia el interior de las Galias a partir de los puertos ibéricos de la costa. 
El triángulo aquitano ha proporcionado, en cambio, numeroso material onomástico, consistente en nombres de persona y de divinidad, trasmitido en epígrafes latinos de época alto-imperial, entre los ss. I-III d. C., que son fiel reflejo de la lengua autóctona de la región. No todo el territorio es homogéneo en cuanto a la distribución de las evidencias onomásticas; ello depende en primer término de la distribución de los propios soportes epigráficos latinos, principalmente lápidas funerarias y aras votivas. Un mapa de localización de los epígrafes latinos nos muestra una clara diferencia entre la Aquitania oriental, formada por los valles pirenaicos tributarios del río Garona y la llanura del Gers al norte, y la Aquitania occidental, a la que pertenecen las tierras drenadas por el río Adour y la zona pantanosa y poco poblada de las Landas. A la zona oriental de Aquitania pertenecen los pueblos pirenaicos de los Conuenae y los Consorani, además de los Ausci de la llanura, que según Estrabón eran los más importantes de los aquitanos. Su territorio ha proporcionado gran cantidad de epigrafía latina, no solamente en los núcleos urbanos de sus respectivas ciuitates, Lugdunum Conuenarum - Saint-Bertrand-de-Comminges y Elimberris Auscorum - Auch, sino también en todo el territorio rural perteneciente a su jurisdicción, especialmente en los altos valles pirenaicos. La Aquitania occidental, en cambio, es más parca en epígrafes, estando limitados por lo general a los núcleos urbanos de las ciuitates, como Aquis Tarbellicis - Dax o Atura - Aire-sur-Adour. Esta distribución de la epigrafía latina en Aquitania es una muestra del carácter más romanizado de la zona oriental, limítrofe de la provincia narbonense, que antes de la conquista tuvo contactos comerciales más estrechos con las sociedades avanzadas mediterráneas. ${ }^{4}$

Si nos atenemos ahora a la distribución de la onomástica indígena vehiculada a través de los epígrafes latinos, la diferencia es aún mayor, si cabe, porque se limita casi exclusivamente a la parte oriental, en la que se atestiguan todos los nombres personales y la mayoría de los teónimos, a excepción de las dedicaciones a dos divinidades indígenas en la zona occidental. Aunque parezca paradójica la mayor frecuencia de nombres de persona indígenas en la zona más romanizada de Aquitania, dicha abundancia se debe a que el hábito epigráfico alcanzó a capas numerosas de población peregrina, que aún conservaban sus nombres indígenas, mientras que en la zona occidental

4 La diferencia entre la Aquitania oriental y occidental se aprecia también en otros ámbitos culturales, como la producción de monedas y de cerámica de diferentes tipos. Véase Hiriart et al. 2018. 
el hábito epigráfico quedó limitado a los ciues romani y su cercano círculo de influencia, a juzgar por la documentación epigráfica conservada.

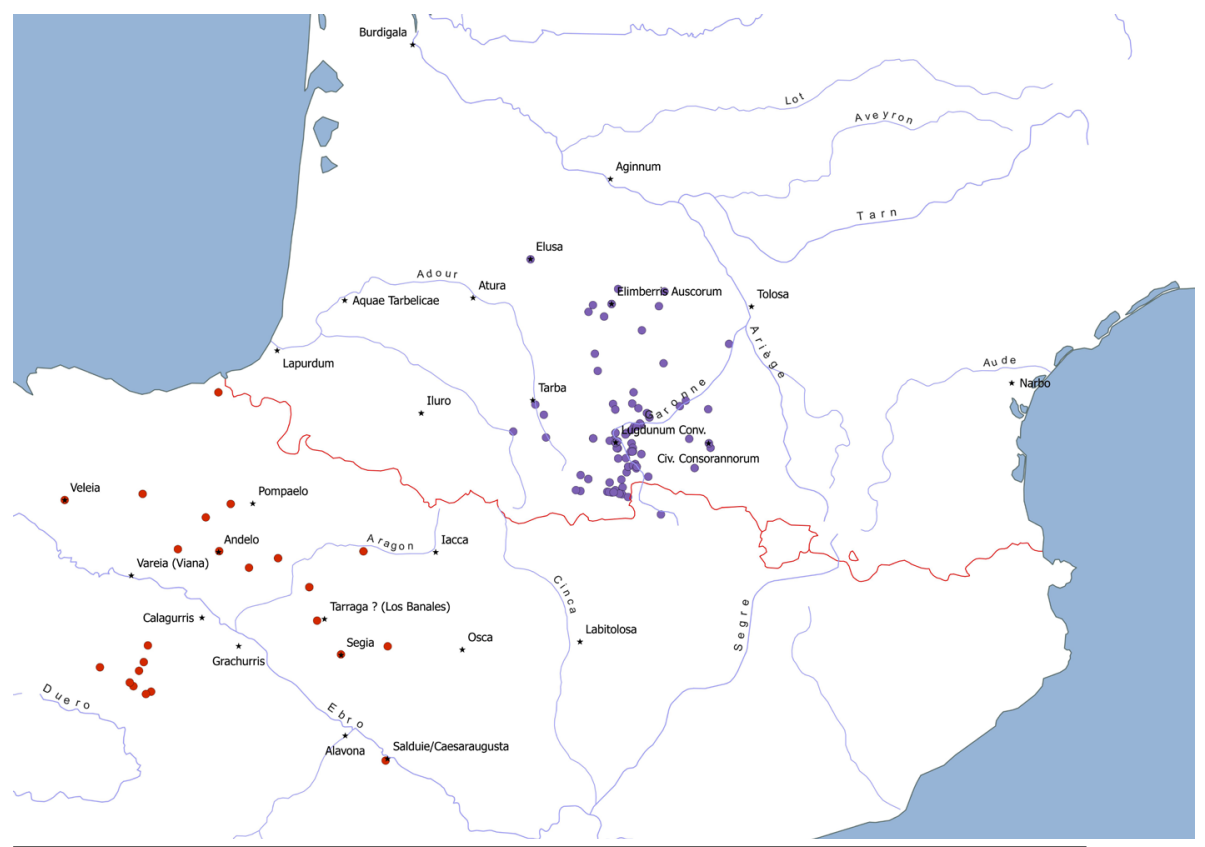

Mapa. 2. Distribución de los antropónimos aquitanos y vascónicos documentados en inscripciones latinas de época republicana e imperial.

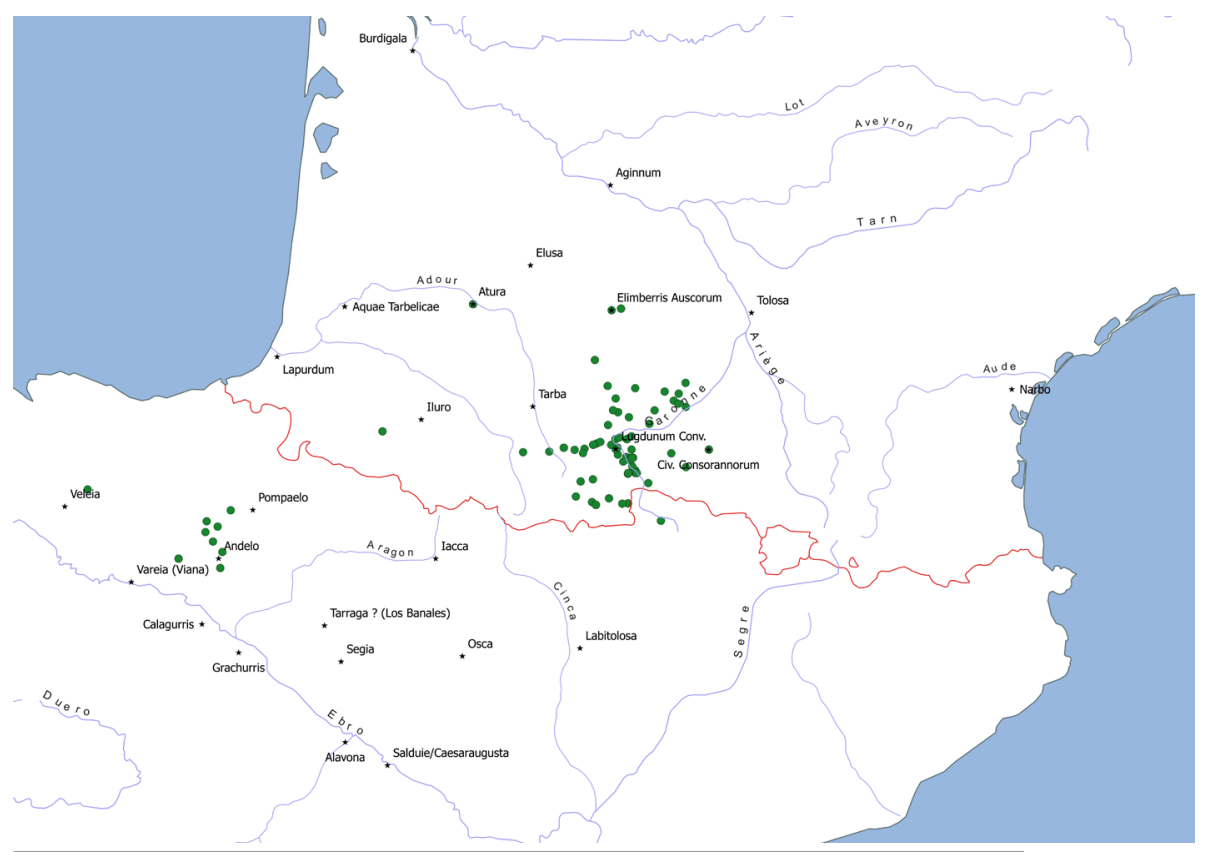

$\overline{\text { Mapa. 3. Distribución de los teónimos aquitanos y vascónicos documentados en }}$ inscripciones latinas de epoca imperial. 
A falta de área epigráfica indígena tenemos un conjunto de nombres propios indígenas, que sin embargo no podemos asignarlos todos a la lengua autóctona aquitana, ya que en ese conjunto se perciben al menos dos grupos bien diferenciados en cuanto a su origen lingüístico: a) unos son galos, similares a los que se atestiguan en otros lugares de las Galias, y b) otros son exclusivamente locales y explicables a través de la lengua vasca. Entre los galos hallamos compuestos como Casidanni, Cintugnati Dannorigis, etc., o simples y derivados como Camuli, Dannoni, Sintus, Trocci, etc., formados sobre elementos onomásticos galos bien conocidos (cintu- 'primero', gnato- 'nacido', danno- 'juez' o designación de magistrado, donno- 'noble', rig- 'rey'; camulo'sirviente', litano-'ancho', sentu- 'camino', trougo- 'infeliz'). Más abajo daremos cuenta de los nombres aquitanos. Por lo general es factible hacer una clasificación sin demasiados problemas, debido a la diferente estructura morfológica y fonológica de las lenguas que soportan ambos grupos, el galo céltico por un lado y el vasco por otro, que conocemos bien, pero en nombres cortos y en aquellos con características ambiguas o no especialmente reveladoras la clasificación se vuelve más insegura. Volveremos sobre este problema en la segunda parte.

En cuanto a la localización de los nombres aquitanos, por el este no sobrepasan los límites provinciales, salvo en casos aislados explicables por movilidad de individuos (la dedicación a Herculi Ilunno Andose de Narbona) y por el norte va menguando su frecuencia a medida que se alejan de los Pirineos sin alcanzar nunca las tierras más cercanas al Garona; la zona de Burdeos es territorio galo; los escasísimos testimonios de las Landas, el Béarn y el País Vasco se asignan a esta área onomástica aquitana.

La situación lingüística de los Pirineos occidentales al sur de la cadena, en el territorio vascón y aledaño, es mucho más compleja que la aquitana por varios factores; en primer lugar, aunque existen acuñaciones de moneda ibérica y se documentan unos textos indígenas fragmentarios, la información lingüística obtenida de ellos, además de escasa, no es muy característica; en cuanto a la onomástica personal, el territorio vascón en época imperial proporciona un conjunto de nombres indígenas mucho más reducido que Aquitania, que es indicio de una relativamente temprana romanización onomástica, si la comparamos con la situación ofrecida por los datos republicanos y en especial por los nombres trasmitidos en el bronce de Áscoli del 89 a. C. (CIL I $\left.\mathrm{I}^{2}, 709\right)$; por último, los documentos remiten a la presencia de más de una lengua en todo este territorio, siendo la vascónica una de ellas, habiendo 
claros testimonios de onomástica céltica en las zonas más occidentales y de onomástica ibérica cuanto más al este. Al igual que en las zonas menos romanizadas de la Aquitania atlántica, también la vertiente cantábrica presenta la paradoja de proporcionar nombres casi exclusivamente latinos con carencia de nombres indígenas. Estos, nombres de origen céltico en su gran mayoría, se documentan en la vertiente meridional cantábrica perteneciente a los Caristios y Várdulos. En la zona de Estella se documenta una curiosa repartición entre nombres de persona con vinculaciones con la zona várdula y nombres de divinidad de origen éuscaro. Hallazgos epigráficos recientes de la zona de los altos valles sorianos del Cidacos y el Linares han proporcionado nombres de persona de filiación vascona.

Los epígrafes paleohispánicos bien identificados procedentes de las zonas cercanas muestran la presencia de la lengua celtibérica en territorio berón, concretamente en Vareia (antigua ciudad ribereña del Ebro, situada previamente en La Custodia, Viana, Navarra, de donde procede una serie de téseras celtibéricas), y de lengua ibérica en la zona del Ebro medio, hacia Zaragoza, la antigua Salduie. Como se ha dicho antes, los textos indígenas del territorio son muy poco informativos desde el punto de vista lingüístico. Por otro lado, la presencia de testimonios ibéricos puede ser interpretada más bien como un fenómeno de difusión cultural que como reflejo de la presencia de comunidades de habla ibérica. La adopción fonética a hábitos articulatorios vascones sufrida por algunos nombres de origen ibérico, como Ordunetsi o Urchatetelli, es un ejemplo de la presencia de dicha onomástica ibérica en un medio lingüístico vascón.

\subsubsection{Historia de la investigación sobre el vascónico}

A pesar de las tempranas noticias de Estrabón que unía los pueblos aquitanos más a los iberos que a los galos, la erudición renacentista trataba a los aquitanos como parte de la Galia y a los vascones como el pueblo que había mantenido la antigua lengua prerromana de la península. La presencia de la lengua vasca en las provincias vascas continentales de Labourd, Baja Navarra y Soule se explicaba como consecuencia de las incursiones vasconas hacia el norte en época merovingia, tomando como apoyo el relato de Gre- 
gorio de Tours (Historia Francorum, año 587); ${ }^{5}$ es la idea de A. Oihenart que se mantiene hasta las investigaciones de Humboldt y Luchaire. De manera complementaria, la erudición renacentista consideraba la lengua vasca como la descendiente de la antigua lengua universal y general de la península, estableciéndose de este modo en los Pirineos una barrera lingüística y cultural que colocaba al norte a los celtas galos y al sur a los vasco-ibéricos no indoeuropeos.

Hay que mencionar a W. von Humboldt, cuya obra Prüfung $(1821)^{6}$ fue enormemente influyente para la investigación de las antigüedades hispanas, por su riqueza en datos comparativos, comentarios metodológicos e investigación histórica y etnológica. Sin embargo, los investigadores posteriores solamente retuvieron su idea de la identidad vasco-ibérica. Humboldt vinculó la Aquitania a Iberia, haciéndola parte integral de la antigua área vasca. Reunió algunos topónimos aquitanos que mostraban llamativas similitudes con otros nombres hispanos, como Calagorris, hoy Saint-Martory (HG) (Itin. Ant.) y Calagurris junto al Ebro, hoy Calahorra; Elimberrum, capital de los Auscii (hoy Auch), idéntico a Ilumberri de Navarra y otras Iliberri hispanas; Iluro, hoy Oloron, e Iluro de los Cossetani (en la costa catalana); Bigerri, pueblo localizado en Bigorre, cuya etimología vasca dio por segura ( $b i$ 'dos' gora 'arriba'). Añade además un argumento negativo: la ausencia de verdaderos topónimos celtas terminados en -briga, -dunum, -magus o -vices.

El conocimiento sobre la situación lingüística experimentó un avance crucial con la investigación llevada a cabo por el archivista A. Luchaire en el último cuarto del s. XIX, especialmente en su artículo Les origines linguistiques de l'Aquitaine, ${ }^{7}$ donde es capaz de presentar los datos de una manera clara y convincente. En primer lugar, recoge todos los nombres propios de persona y de divinidad trasmitidos en epígrafes latinos, con un intento de explicación lingüística, que se añaden ahora por vez primera a los datos de naturaleza

$5 \quad$ Wascones vero de montibus prorrumpentes in plana descendunt, vineas agrosque depopulantes, domus tradentes incendio, nonnullos abducentes captivos cum pecoribus. Contra eos saepius Austrovaldus dux processit, sed parvam ultionem exegit ab eis (Monumenta Germaniae IX,7, 363). Año 587. "The Basques descended from the mountains into the plain, devastated cities, fields, set fire to houses and took some captives with their herds. The Duke Austrevald often went against them, but hardly managed to take vengeance".

6 W. von Humboldt, Prüfung der Untersuchungen über die Urbewohner Hispaniens (Review of research on the first inhabitants of Hispania - 1821)

7 A. Luchaire, "Les Origines linguistiques de l'Aquitaine", Bul. Soc. Sciences, Lettres et Arts de Pau, 1876/7, 349-423, seguido más tarde por Études sur les idiomes Pyrénéens de la région française, Paris 1879 (facsim. Genève 1973). 
toponímica que eran los únicos usados previamente en la investigación. En segundo lugar, establece una relación entre los nombres antiguos y los atestiguados en las cartas medievales, mostrando una continuidad ininterrumpida entre los tiempos antiguos y modernos, donde la documentación vasca medieval funciona como eslabón de unión en la cadena. Por último, llama la atención sobre los rasgos más sobresalientes de la lengua vasca y de la lengua gascona - cuyo dominio territorial coincide con el de la antigua Aquitania-, de modo que podemos entender las similitudes existentes entre ellas como el resultado de un proceso de sustitución de una (la vasco-aquitana) por la otra (latín-gascón), explicables en términos de sustrato lingüístico. Los logros alcanzados por Luchaire fueron asumidos unánimemente por la investigación posterior, aunque inmersos en la teoría más general del vasco-iberismo. Así, E. Hübner, el autor de Monumenta Linguae Ibericae, usó el material aquitano recogido por Luchaire como si fuera propiamente ibérico, y el gran romanista H. Schuchardt avanzó explicaciones de los nombres ibéricos del bronce de Áscoli mediante comparaciones con los nombres aquitanos y la lengua vasca.

El siguiente gran avance en nuestro conocimiento de las lenguas indígenas peninsulares se debió al desciframiento de la escritura ibérica por M. Gómez Moreno en 1925 y años siguientes. Entre las consecuencias importantes del desciframiento cabe mencionar:

a) la presencia de dos lenguas completamente diferentes, el celtibérico y el ibérico, en las inscripciones indígenas que previamente eran consideradas como pertenecientes a una única lengua,

b) la esterilidad de la comparación vasca aplicada a la comprensión de los textos ibéricos, que permanecieron tan oscuros como antes, a pesar de que ahora se podían leer los textos con garantías.

La primera de las consecuencias citadas fue aceptada por todos los investigadores, y quedó reflejada en la división bipartita de la península en una Hispania indoeuropea, caracterizada por la difusión de topónimos en -briga, y una Hispania no-indoeuropea con topónimos en -ili, -ilu, según quedaba patente en los mapas de distribución publicados en los años 60 por J. Untermann. En cambio, la idea de una relación entre el vasco y el ibérico nunca ha desaparecido por completo, aunque el desciframiento trajo un descrédito definitivo de la práctica metodológica del emparejamiento mecánico de palabras superficialmente idénticas; los investigadores buscan ahora comprender los textos por medios internos, utilizando técnicas de análisis filológico y combinación de morfemas sin apelar directamente al léxico vasco. Los nuevos 
hallazgos tuvieron un doble efecto en cuanto a la posición de la lengua vasca: mientras que por un lado deshacían la supuesta identidad con el ibérico, tal como la defendía la tradicional hipótesis vasco-iberista, por otro, fortalecían los vínculos con la variedad lingüística aquitana, haciendo de la lengua vasca no la universal y general de la península ibérica sino una lengua fundamentalmente pirenaica, para algunos incluso estrictamente continental.

Así, en este sentido, ya Gómez Moreno señaló que los testimonios de material vasco al sur de los Pirineos y especialmente en el País Vasco eran inexistentes o muy raros, en comparación con su abundancia en Aquitania. Por esta razón, algunos autores propusieron el carácter continental de la lengua vasca, es decir, que el foco originario de la lengua estaba en Aquitania, y solo más tarde, probablemente en la antigüedad tardía, habría traspasado los Pirineos hacia el sur. Esta fue la opinión de Schmoll 1959, 25 n.1, ${ }^{8}$ y es la opinión actual de otros investigadores como J. Abaitua \& M. Unzueta 2011 y F. Villar et al. 2005, 503 y ss. ${ }^{9}$

En las últimas tres décadas hallazgos epigráficos, tanto de textos paleohispánicos como de onomástica indígena en epígrafes latinos, han cambiado drásticamente el panorama en territorio vascón. La estela de Lerga, las inscripciones procedentes de la comarca de Cinco Villas de Aragón y especialmente los altares votivos con teonimia vascona de la zona de Estella han proporcionado material onomástico con evidentes vinculaciones tanto con el vasco como con el aquitano. A este conjunto se ha añadido recientemente un grupo de nombres de persona localizados en las Tierras Altas de Soria, en las cabeceras de los ríos Cidacos y Linares, territorio que pertenecía a la jurisdicción de la ciudad vascona de Calagurris.

$8 \quad$ U. Schmoll 1959: Die Sprachen der vorkeltischen Indogermanen Hispaniens und das Keltiberische, "Mit anderen Worten: die massgebliche Schicht der Bevölkerung Vaskoniens war indogermanisch. Die vaskonischen PN, die Gómez Moreno Misceláneas, S. $239 f$. zusammengestellt hat, gehören in grosser Mehrzahl zu dieser idg.-keltischen Schicht. Aquitanisch-baskische (auskische) oder iberische Namen fehlen nicht völlig, sind aber mit einer Spärlichkeit vertreten, die nur den Schluss zulässt, dass diese Schicht weitgehend zurückgedrangt war. Dies ist zugleich ein Beweis dafür, dass das heute in diesen Gebieten herrschende Baskentum im wesentlichen auf spätere Einwanderung aus Aquitanien zurückgeht" (p. 25, n. 1).

9 Mientras que Schmoll suponía que hubo una capa éuskara antigua que cedió ante una indoeuropeización posterior, para ser de nuevo revasconizada en época tardo-antigua, Villar defiende, en base a un análisis etimológico de la toponimia antigua, la naturaleza indoeuropea antiquísima de todo el norte peninsular, en realidad de todo el refugio cántabro-pirenaico en el último máximo glacial, de modo que los testimonios vascones de época romana son señales de incursión relativamente moderna. 


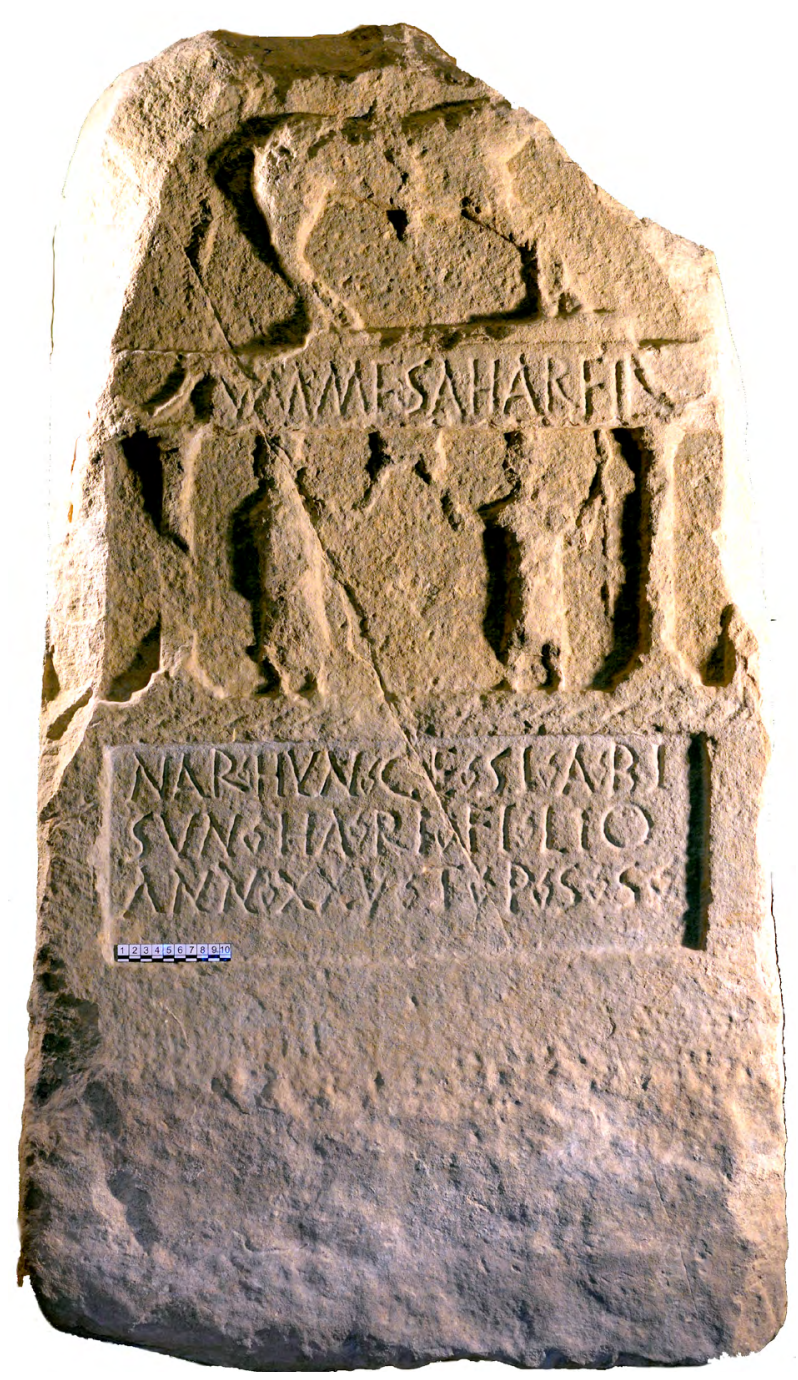

Fig. 1. Estela de Lerga, Navarra (HEp 7, 470). Lectura: Ummesahar fi(lius) // Narhungesi Abi/sunhari filio /ann(orum) XXV t(itulum) p(osuit) s(umpto) $s($ uo $)$. Museo de Navarra. Foto: J. Gorrochategui.

\subsubsection{Historia de la investigación sobre el aquitano.}

La onomástica aquitana, tras los pioneros estudios de A. Luchaire, recibió una explicación lingüística satisfactoria por L. Michelena en su artículo "De onomástica aquitana" (Pirineos 1954, 409-458), donde analizó los elementos constitutivos de los nombres, los modos de formación y sus rasgos fonéticos, poniéndolos en relación con fenómenos de la lengua vasca. El trabajo tuvo continuación en la monografía de J. Gorrochategui, Onomástica indígena de Aquitania (1984), donde se recopilan exhaustivamente todos los nombres de persona y de divinidad indígenas de Aquitania novempopulana, tanto 
aquitanos como galos, seguidos de un estudio lingüístico del material. En la obra también se recogen los escasos nombres vascónicos conocidos en aquel momento.

La publicación del hallazgo del tesoro de Hagenbach (H. Bernhard, H.-J. Engels, R. Engels, R. Petrovszky, Der römische Schatzfund von Hagenbach, Mainz 1990) proporcionó nuevo material onomástico aquitano de gran interés lingüístico, que fue analizado por J. Gorrochategui, "Las placas votivas de plata de origen aquitano halladas en Hagenbach, Renania-Palatinado, Alemania", Revue Aquitania 19, 2003, 25-47). Las láminas no solo proporcionan nombres desconocidos previamente, sino que aportan también variantes gráficas de otros ya conocidos, que suscitan cuestiones lingüísticas de cierta trascendencia, como el de la existencia de palatalización expresiva y su anotación gráfica. Este artículo y otros sobre aspectos concretos de onomástica aquitana se recogen en el libro de B. Urgell y J. M. Vallejo (eds.), Opera selecta Joaquín Gorrochategui I. Aquitanica /Akitaniera, Vitoria-Gasteiz 2018.

Un estado de la cuestión muy actualizado se recoge en dos trabajos recientes de Gorrochategui: a) "La lengua vasca en la antigüedad", J. Gorrochategui, I. Igartua, J. A. Lakarra (eds.), Historia de la Lengua Vasca, Vitoria-Gasteiz 2018, 245-305 y b) Aquitano y Vascónico [AELAW Booklet 9], Zaragoza 2020.

La documentación vascona recibió una atención específica por parte de Gorrochategui, "Situación lingüística de Navarra y aledaños en la antigüedad a partir de las fuentes epigráficas", Primer Congreso general de Historia de Navarra, 2, 1987, 435-445, y más tarde por parte de J. L. Ramírez Sádaba, "La onomástica de los vascones: autóctonos e inmigrantes", Príncipe de Viana. Anejo, $\mathrm{n}^{\circ}$ 14, 1992, 287-293. Fue tratada también, en un marco más general pirenaico, por J. de Hoz, "El poblamiento antiguo de los Pirineos desde el punto de vista lingüístico", J. Bertranpetit \& E. Vives (eds.), Muntanyes i població. El passat dels Pirineus des d'una perspectiva multidisciplinària, Andorra la Vella, 1995, 271-299. La especificidad de las gentes de los altos valles del Cidacos y Linares, desde un punto de vista cultural y epigráfico, fue puesta de manifiesto por U. Espinosa y L. M. Usero, "Eine Hirtenkultur im Umbruch Untersuchungen zu einer Gruppe von Inschriften aus dem conventus Caesaraugustanus (Hispania Citerior)", Chiron 18, 1988, 477-504, mientras que el origen vascón de su antroponimia personal ha sido tratado por J. Gorrochategui, "Vasco antiguo: algunas cuestiones de geografía e historia lingüísticas", Palaeohispanica 9 [= Acta palaeohispanica X. Actas do X Colóquio sobre linguas e culturas paleo-hispânicas], 2009, 539-555. 
Sobre las relaciones lingüísticas de la lengua vasca con el ibérico, véase el trabajo reciente de E. Orduña, “The Vasco-Iberian theory”, A. G. Sinner y J. Velaza, (eds.), Palaeohispanic languages and epigraphies, Oxford, 2019, 219-239, en el que pasa revista a los argumentos utilizados en las diversas fases y acepciones de la teoría vasco-iberista. Para las relaciones lingüísticas entre el vascón y el aquitano y su posición en relación a la lengua vasca histórica, véase J. Gorrochategui, “The relationship between Aquitanian and Basque: Achievements and challenges of the comparative method in a context of poor documentation", en: Th. Chacon, N. Lee, y W. Silva (eds.). Language Change, Description and Documentation: Studies in Honour of Lyle Campbell, Edinburgh en prensa.

En los últimos años se han puesto a disposición pública corpora on line tanto de textos paleohispánicos como de inscripciones latinas con onomástica indígena. Para los textos paleohispánicos contamos con la Base de Datos Hesperia de Lenguas y Epigrafía Paleohispánica (<http://hesperia.ucm.es/index. php $>$ ), en cuya zona E epigráfica se recogen los escasos textos no celtibéricos de Navarra. El banco numismático recoge toda la acuñación con leyendas paleohispánicas de la zona, mientras que en el banco onomástico se puede consultar la distribución de los nombres propios. Dicha documentación numismática y onomástica puede consultarse también, en formato PDF, en sendas publicaciones: Estarán et al. 2015 y Vallejo 2016. Por último, La página web de E. Orduña (<http://eorduna.awardspace.info/cat/insc aquitanes.

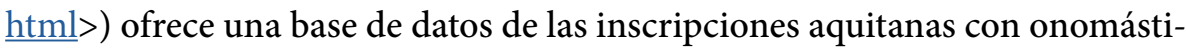
ca indígena aquitana.

\subsection{Descripción lingüística}

De entre los nombres con una distribución exclusivamente limitada al territorio aquitano, podemos enumerar un conjunto amplio que presenta similitudes muy evidentes con términos vascos.

- Nombres formados sobre designaciones de individuos o de parentesco: Cison, Cisson-bonnis (gen.), Cison-ten, en nombres de varones ( $c f$. vasco gizon 'hombre, varón'); Andere, Andere-ni (dat.), Andere-seni (dat.), Andre-cconi (dat.), en nombres de mujer (vasco andere 'señora'); Sembe-coni (dat.), Sembe-tar, Sembe-tennis (gen.), Sembus, siempre como nombres de varón ( $c f$. vasco seme 'hijo'); Seni-cco, Seni-tennis (gen.), Seni-xsonis (gen.), en varones (cf. vasco sehi 'muchacho'); Hanna-bi (gen.), Hanna, Hanna-c(o), cf. vasco anaia 'hermano', y el nombre de mujer Nescato ( $c f$. vasco neska, neskato 'muchacha'). 
- Nombres sobre designaciones de animales: Aher-belste (teón.), cf. vasco akher 'macho cabrío'; Asto-ilunno (teón.), cf. vasco arsto, asto 'burro'; Harsi (gen), Hars-pi (gen), cf. vasco hartz 'oso'; Heraus-corritsehe (teón.), cf. herauts 'verraco'; Oxson, cf. otso 'lobo'.

- Teónimos sobre designaciones de árboles: [H]arexo, Arixoni, $c f$. vasco hareitz 'roble'; Artehe, Artahe, $c f$. vasco arte 'encina'; quizás Leherenn, $c f$. vasco leher 'pino'.

- Otros nombres: Belex, Belex-conis (gen), Belex-eia, Bon-belex, Har-belex, cf. vasco bel-, beltz 'negro'; teónimos Bai-gorixo, Lur-gorr[, Heraus-corri-tsehe, $c f$. vasco gorri 'rojo, pelado'; Iluni, Ilunni (teón..), cf. vasco il(h)un 'obscuro'; Enne-box, $c f$. el nombre vasco medieval Enneco.

El núcleo de los nombres aquitanos está formado por elementos bien relacionados con palabras del vascón común. Otros nombres, sin embargo, carecen de una etimología vasca conocida, aunque presentan rasgos fonéticos y morfológicos que son desconocidos o muy raros en galo, pero completamente compatibles con los definidos para la lengua vasca.

Fig. 2. Altar dedicado a Hércules Ilun Andos, CIL XII 4316 (Narbona). Lectura: Cn(aeus) Pompeius / Cn(aei) l(ibertus) Hyla / Herculi / Ilunno Andose / $v$ (otum) s(olvit) l(ibens) m(erito).

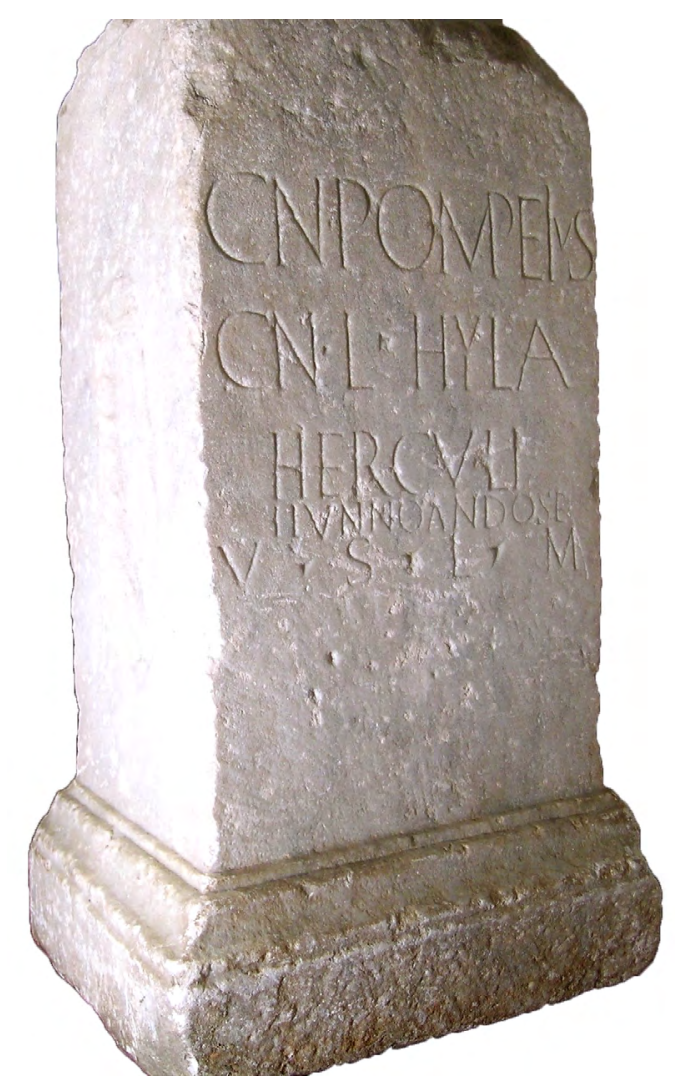




\subsubsection{Rasgos lingüísticos.}

En primer lugar, en cuanto al tipo de formación nominal, el aquitano es rico en nombres derivados, mientras que el número de nombres compuestos es bajo y limitado casi exclusivamente a los nombres de divinidad. Solamente se atestiguan sufijos; los prefijos, tan abundantes en galo (cf. uer-, com-, ad-, an-, at(e)-, eni-, ro-), son inexistentes. En cuanto a su estructura, unos tienen aspecto de mero alargamiento, consistente en una consonante nasal (- $n n$, -enn) o sibilante (-xs, -ass, -iss), mientras que el resto presenta un esquema $-\mathrm{KV}(\mathrm{R})$ : - $c o$, -to, -ten, -tar, donde la primera consonante es sorda.

Junto a palabras bisílabas terminadas en vocal (como sembe-, ombe-, seni-, neska-, arte-, hanna-, berri-, gorri-, enne-, erhe-, gere-, lohi-) y en consonante no oclusiva (andox-, belex-, berhax-, cis(s)on-, edun-, harex-, hahan-, hauten-), hay un conjunto pequeño de nombres monosílabos, con una estructura de consonante + vocal + consonante no-oclusiva: bon-, bors-, hals-, har-, hars-, hiss-, tals-.

Si observamos el inventario de fonemas y sus combinaciones representados en los nombres aquitanos, destacan los siguientes rasgos:

El sistema consonántico estaba articulado mediante una oposición de intensidad que oponía consonantes fuertes o tensas a consonantes lenes o laxas. Las primeras se grafían por lo general mediante las sordas latinas, a veces acompañadas de aspiración, mientras que las segundas se adaptan mediante las consonantes sonoras, aunque a veces en posición inicial aparezcan sordas. En las sonorantes, especialmente en la nasal/n/, la oposición se anota mediante geminada $\mathrm{NN}$ para la articulación tensa y simple $\mathrm{N}$ para la laxa, mientras que en las sibilantes la grafía $\mathrm{X}(\mathrm{S})$ se usa para la variante fuerte, articulada probablemente como africada, y la $S$ para la lene, articulada como fricativa. No había fricativas $/ \mathrm{f} /, / \theta /, / \mathrm{x} /$, de las cuales solamente la primera entró a formar parte del sistema vasco en épocas posteriores. Llama la atención que el único fonema labial verdaderamente funcional fuera la $/ \mathrm{b} /$, ya que la $/ \mathrm{p} / \mathrm{y}$ la $/ \mathrm{m} /$ eran marginales. Este sistema es idéntico o muy parecido al del protovasco reconstruido a partir de los dialectos vascos históricos. 
a) Consonantes

\begin{tabular}{|c|c|c|c|c|c|c|c|c|}
\cline { 2 - 9 } \multicolumn{1}{c|}{} & \multicolumn{3}{c|}{ oclusivas } & \multicolumn{2}{c|}{ sibilantes } & \multicolumn{3}{c|}{ Sonorantes } \\
\cline { 2 - 9 } \multicolumn{1}{c|}{} & labial & dental & velar & apical & laminal & nasal & lateral & rótica \\
\hline fortis & $(-)$ & $\mathrm{t}$ & $\mathrm{k}$ & $\mathrm{ts}$ & $\mathrm{ts}$ & $\mathrm{N}$ & $\mathrm{L}$ & $\mathrm{R}$ \\
\hline lenis & $\mathrm{b}$ & $\mathrm{d}$ & $\mathrm{g}$ & $\mathrm{S}$ & $\mathrm{s}$ & $\mathrm{n}$ & $\mathrm{L}$ & $\mathrm{r}$ \\
\hline
\end{tabular}

b) Vocales

\begin{tabular}{|c|c|c|c|}
\cline { 2 - 4 } \multicolumn{1}{c|}{} & anterior & central & posterior \\
\hline alta & $\mathrm{i}$ & & $\mathrm{u}$ \\
\hline media & $\mathrm{e}$ & & $\mathrm{o}$ \\
\hline baja & & $\mathrm{a}$ & \\
\hline
\end{tabular}

La oposición de tensión en las sonorantes /n, r, 1/ queda limitada a la posición intervocálica, mientras que en inicial de palabra solo hallamos variante laxa o lenis y en final de palabra o tema (antes de las desinencias latinas) variante tensa ofortis.

Inicial: Nescato, Narhonsus, en medial: Seni-, Dunoho- vs. Hanna-, Enne-; en final de tema: Sembetenn-is, Edunn-is, Hahann-is, etc.

Las sibilantes se comportan del mismo modo, oponiéndose en medial de palabra y neutralizándose en inicial a favor de las fricativas y en final de tema a favor de las africadas.

Inicial S: Sembe-, Seni-, Silex-, Medial: Cison, Sosonnis vs. Oxson, Anderexso; en final de tema: Belex, Berhaxs-is, Silexs-i.

Algunos de los rasgos característicos del aquitano, en contraposición a las lenguas cercanas, eran:

A) Amplia presencia de $\mathrm{H}$ en todas las posiciones de la palabra, especialmente en inicial (Hautense, Harsi) y entre vocales (Aherbelste). Es especialmente frecuente entre vocales idénticas (Uloho-, Hahan-, Leherenn) y tras sonantes (Erhexo-, Lelhunn-), aunque a veces no se anote (Ereseni, Leren). A diferencia del vasco histórico, la aspiración no quedaba limitada a las dos sílabas iniciales de la palabra ni a una sola aspiración por palabra (p.ej. Hahanten). La aspiración es un rasgo que caracteriza al aquitano, vinculándolo con la lengua vasca y separándolo de las lenguas circundantes como el galo, el celtibérico y el ibérico. 


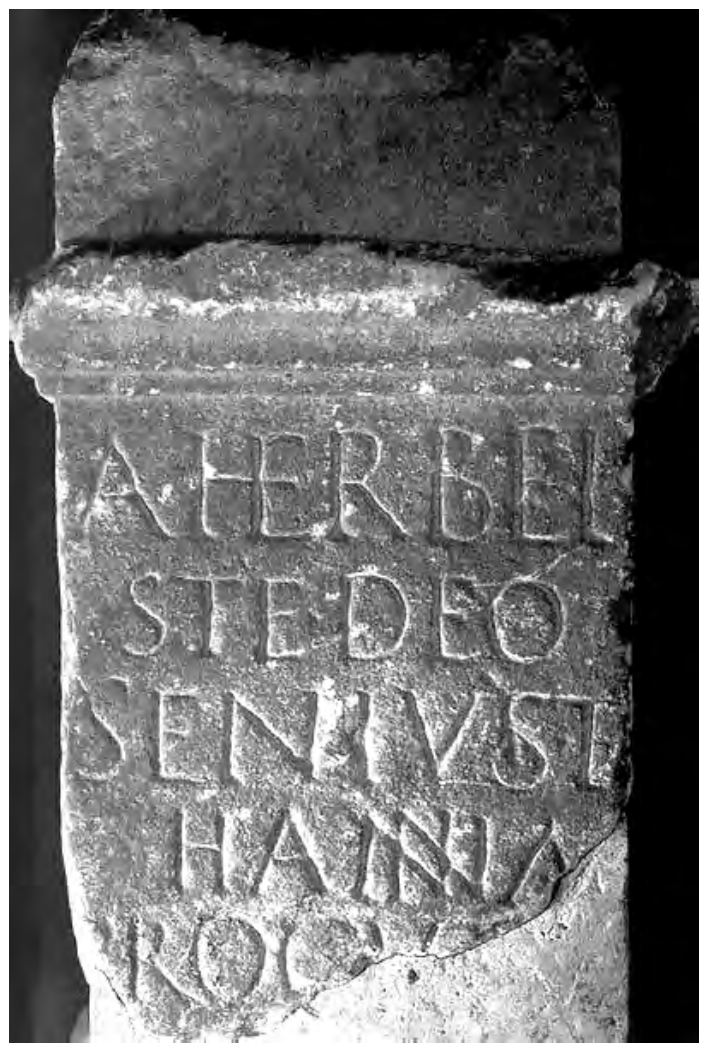

Fig. 3. Altar dedicado a Aherbelste, CIL XIII, 174 (Landorthe, Alto Garona). Lectura: Aherbel/ste deo / Senius et / Hanna / Procul(if?).

B) Escasez de M. En los nombres de origen aquitano, $/ \mathrm{m} /$ es particularmente rara. En inicial solo se documenta en Monsus, que es variante del común Bonxus. En medial está casi limitado al grupo -mb-(Sembe-, Ombe-), donde se entiende como alófono de $/ \mathrm{n} /$ ante labial. En cambio, $/ \mathrm{m} /$ es muy frecuente en los nombres galos (Matico, Dunomagius, Solimuti, etc.). La intervocálica M en Somenaris, de ser aquitano, puede explicarse por influencia de /n/ de la sílaba siguiente; esto recuerda un cambio idéntico ocurrido en vasco: Lat. vagina $>$ magina, Lat. vindicare $>$ mendekatu entre los préstamos o ${ }^{\star}$ bini $>$ *mini > mihi 'lengua' en el léxico patrimonial.

C) Carencia de R- inicial. En el corpus de los nombres indígenas de Aquitania, consistente en alrededor de 600 nombres, solo uno comienza por R-, y es de origen galo: Remo (dat), individuo de la ciudad de los Remi. Este fenómeno diferencia al aquitano del resto de las lenguas célticas vecinas, como el galo, que no tenían esta restricción. Se trata de un rasgo que el aquitano comparte con el ibérico y con el vasco histórico, que lo ha mantenido hasta hoy, $c f$. Lat. $\operatorname{rota}(m)>$ errota 'molino'; rege $(m)>$ errege 'rey'. 


\subsection{Los textos}

Como hemos dicho anteriormente, el único texto indígena hallado en Aquitania hasta ahora (la pátera de Vieille-Aubagnan, BDH LAN.01.01) está escrito en ibérico y corresponde a una producción artesanal del Levante ibérico. Tampoco todos los textos paleohispánicos procedentes del territorio vascón están libres de la sospecha de ser textos importados o de haber sido redactados por personas foráneas.

Los textos hallados hasta el momento son los siguientes:

- Bronce de Aranguren (NA.05.01). Opistógrafo y gravemente mutilado. Las secuencias conservadas no permiten ninguna clara identificación con ninguna de las lenguas conocidas, aunque la probable existencia de signos para dos vibrantes lo apartaría del celtibérico, a cuyo ámbito lo relaciona, sin embargo, el material del soporte: bronce. Pudo haber sido escrito en otro lugar.

- Lápida de Olite (NA.06.01). Conserva solamente la secuencia ]en : $\mathbf{s}[$ en sentido levógiro. La gran magnitud de las letras obliga a pensar en una lápida de grandes dimensiones, escrita in situ. La secuencia es poco compatible con la lengua celtibérica tanto por el final como por el inicio de palabra y compatible tanto con ibérico como con vascón.

- Lápida de Cabezo Lobo, Bardenas Reales (NA.12.01). Difícil texto o textos en escritura latina, con secuencias sin paralelos; la presencia de $p$, inicio con $r$-y secuencia - $r$ - no se compadecen con el vascónico ni con el ibérico.

- Grafito de Alfaro (LO.04.02). La leyenda lueikar[, probable expresión de propiedad, no tiene buenos paralelos, aunque la terminación -kar, de estar completo, es muy frecuente como final de NP en la onomástica ibera.

- Mosaico de Muruzábal de Andión (Andelo) (NA.03.01). Es el único texto completo y bien legible (likine:abuloŕaune:ekien:bilbiliaŕs), con evidentes relaciones lingüísticas y materiales con el mosaico de Caminreal (TE.04.03). Su adscripción lingüística es debatida: aunque generalmente es considerado texto ibérico, hay opiniones que lo toman como testimonio de la lengua local vascónica. Los nombres de persona apuntan a la onomástica celtibérica, ya que likine se explica bien como forma iberizada del nombre celtibérico likinos, mientras que abuloŕaune, con un final -ŕaune nada claro, remite también al nombre de persona celtibérico abulu. Igualmente, la secuencia bilbiliaŕs está basada sobre el topónimo Bilbilis, en aquel momento celtibérica, aunque su 
nombre no lo sea. Como término eminentemente gramatical queda ekien, con evidentes relaciones con ibérico ekiar, aunque sin paralelos hasta el presente. Su aparente forma de pretérito vasco, comparable a vasco zegien 'lo hizo', junto a la localización misma del hallazgo, da argumentos para considerarlo texto vascón, aunque carezca de una sintaxis ergativa, como pediría la lengua vasca para esa forma verbal, ni queden claros los sufijos o terminaciones del texto. Todas estas circunstancias hacen de este texto un exponente de las relaciones culturales y comerciales existentes entre las tres etnias.

- A los mencionados arriba hay que añadir las leyendas monetales de las cecas procedentes del territorio vascón y aledaño. Suelen adscribirse a esta zona las siguientes leyendas: kalakoŕikoś (Calagurris - Calahorra), sekia (Segia - Ejea de los Caballeros), bolśkan (Osca - Huesca) y iaka (Iacca - Jaca) entre las de localización conocida y arsaos, arsakos, baŕśkunes, bentia(n), olkaiŕun, ontikes, sesars, tiŕsos y unambaate. Desde un punto de vista lingüístico, el conjunto no forma parte de ninguna de las dos áreas bien definidas del nordeste hispano: la ibérica, donde las leyendas monetales presentan el sufijo -śken, y la celtibérica que acuñó monedas con leyendas en -koś y -kom. El elemento con mayor verosimilitud de análisis vasco es la - $n$ final de la leyenda bolśkan, que gracias a la comparación con el nombre de la ciudad $O s c a$, puede ser aislada como sufijo o morfema independiente, relacionado con el inesivo vasco; la misma relación hallamos entre las leyendas bentian $\sim$ bentia.

\subsection{La escritura}

Para el material lingüístico trasmitido en escritura paleohispánica se utilizó la variedad ibérica nororiental o levantina, aunque con algunas particularidades dignas de mención. Lo más llamativo es la presencia de algunos grafemas únicos o muy poco usados en otras regiones. La ceca transcrita como arsaos presenta como segundo signo una $R$, semejante a la $R$ latina que en los textos ibéricos narbonenses tiene valor de $/ \mathrm{a} / .{ }^{10} \mathrm{La}$ ceca sesars presenta en segunda posición el signo en forma de espiga, también usado en la epigrafía ibérica narbonense, aunque con valores aún no totalmente claros, pero de todos modos distintos de la /e/ aquí anotada. Por último, las cecas de oTtikes $\mathrm{y}$ de uTanbaate presentan un signo en forma de $\mathrm{T}$ latina, de valor aún no claro, aunque tradicionalmente transcrito como /n/. Estas rarezas paleográficas "apuntan a la existencia de un subsistema de escritura característico de la

10 Formalmente admite también comparación con la $\mathrm{r}$ ibérica marcada del signario dual extendido. 
región noroccidental del valle medio del Ebro" (Beltrán y Velaza 2009, 126). Por otro lado, el carácter multicultural de la zona vascona, percibida en la presencia de onomástica de origen étnico diferente o en el particular cruce de soportes y lengua de modo diferente al alineamiento habitual, se aprecia también en el uso de diferentes variedades de escritura; por ejemplo, la inscripción de Andelo parece estar anotada en escritura celtibérica.

El material onomástico vascónico y aquitano trasmitido en epigrafía latina se sirvió de las letras del alfabeto latino de época imperial para la expresión de los sonidos de la lengua. Algunas distinciones fonológicas, que suponemos existían por razones comparativas, no llegaron a tener expresión gráfica, siendo la más importante la diferencia entre sibilante dorso-alveolar /s/ y la apical /S/ (anotadas en vasco mediante $<\mathrm{z}>\mathrm{y}<\mathrm{s}>$ respectivamente), ya que los correlatos de vasc. gizon 'hombre' y seme 'hijo' se grafían ambos con $\mathrm{S}$ en aquitano, Gison y Sembe-. En cambio se logró un procedimiento sistemático para la anotación de sonidos africados, que como hemos visto funcionaban como los correlatos tensos o fuertes de las sibilantes fricativas; en Aquitania alcanzó rango general el uso de $\mathrm{X}$ o XS para la anotación de los sonidos africados /ts $/$ y /tś / o palatal / $/$ / mientras que la zona vascónica tanto meridional como continental se adoptó la grafía TS: la terminación -xe del téonimo aquitano Buaigorrixe (Valentine, Alto Garona) se escribe -tse- en el teónimo Herauscorritse-he (Tardets, Pirineos Atlánticos), grafía que se atestigua también en el teónimo Sela(i)tse (Barbarin, Navarra). Este uso aquitano de las letras X y XS se diferencia del uso galo, donde tiene el valor fonético de fricativa velar $/ \mathrm{x} /$.

\section{Problemas lingüísticos y epigráficos presentados por la docu- mentación}

\subsection{Problemas lingüísticos}

La documentación conservada del aquitano y del vascónico, tanto por el carácter fundamentalmente onomástico, como por la escasez y fragmentariedad de los epígrafes, plantean problemas de diversa naturaleza.

Uno de ellos atañe a la clasificación lingüística del material onomástico. Los nombres propios constituyen un conjunto autónomo dentro de la lengua, ya que a pesar de que por lo general presentan características fonéticas y morfológicas propias de la lengua en cuestión, carecen del sentido semántico inherente al léxico común de la lengua. 
Al ser precisamente la unión de forma y sentido la base sobre la que se asienta el método comparativo en su cometido de clasificación lingüística, el material onomástico es especialmente problemático para la clasificación, ya que la forma externa de los nombres, al carecer de la restricción impuesta por el sentido, puede ser asignada fácilmente a más de una lengua. Así, algunos nombres procedentes de la Aquitania novempopulana han sido asignados al galo, al ser puestos en relación con términos galos o celtas. Para Senicco, Senitenn, etc. se ha pensado en galo seno- 'viejo', para Oxson en celta $u k s o(n)$ 'buey' y para Andoxsus, Andosto en un étimo indoeuropeo ${ }^{*} n_{0} d o-s_{2}$ - $_{2}$ - 'que está debajo' (Delamarre 2007, 22 y 232). En casos como estos, para encauzar correctamente la clasificación, hay que reparar tanto en aspectos de distribución del nombre como en detalles de su formación. Del análisis de Andoxus y derivados como Andosto, Andosten, Andospon, etc. se obtiene un elemento andox- (y no uno ando-sto-), que, unido al hecho de su empleo exclusivo como nombres de varón, lleva a preferir una relación con palabras vascas, como ordots 'verraco,' bildots 'cordero', que contienen el elemento * dots 'macho'.

Igualmente, la identificación de sufijos -ten, -bon, inexistentes en galo, usados en los nombres Senitenn-, Seniponn-, inclinan a identificar la base senicon vasco sehi, sein 'muchacho' (derivable del protovasco ${ }^{*}$ seni) antes que con galo seno- 'viejo'. Para la unión de Oxson con vasco otso 'lobo' y su asignación al aquitano prima el valor de la grafía X, XS como / ts/ en Aquitania (frente a su valor como / $\chi /$ en Galia), tal como se aprecia en la alternancia gráfica del sufijo -xe (Buaigorri-xe) / -tse (Herauscorri-tse), comentada anteriormente.

A veces es imposible tomar una decisión solo por criterios lingüísticos. Un nombre como Senius puede ser explicado como adaptación al latín del nombre aquitano seni o como nomen latino en -ius a partir del galo senos 'viejo'. Otros elementos asociados con el nombre (onomástica de familiares, ambiente religioso o social, etc.) pueden inclinar la balanza en un sentido o en otro.

Un problema especialmente difícil es la separación entre vascónico e ibérico en la parte hispana del dominio, ya que aquí a los problemas generales descritos se añade la falta de desciframiento del ibérico. Además, tampoco ayuda la similitud de ambas lenguas en muchos aspectos de su inventario fonológico, como la carencia de $/ \mathrm{p} / \mathrm{/} / \mathrm{m} /$ o $r$-inicial, que las opone parejamente a las lenguas célticas circundantes. De todos modos, en algunos casos afortunados somos capaces de identificar rasgos articulatorios exclusivamente vascónicos como la aspiración (representada por $\mathrm{H}$ ) o la africación de sibilante en final de tema (cf. Ordunets-i, dat). 
En la mayoría de los casos, la clasificación lingüística depende de una conjunción de datos de diferente índole, tanto lingüística como distribucional, que se conjugan en mostrar un área onomástica coherente en sus bases, elementos y expansión territorial. Por esa razón, los casos aislados procedentes de zonas alejadas, aunque puedan externamente presentar algunos rasgos parecidos a los señalados para la onomástica aquitana, no tienen el peso suficiente como para ampliar el área onomástica; así, p.ej. Gaisco, nombre documentado en una inscripción recién hallada en Osseja, Cerdaña, Pyr.Or. (Ferrer et al. 2018). A veces se trata de individuos desplazados por diversos motivos, como el caso del militar de la cohors III Aquitanorum cuyo epitafio se descubrió en Ardara, Cerdeña.

Todo el conjunto de argumentos comparativos permite clasificar la onomástica aquitana-vascónica en el dominio lingüístico de la lengua vasca, de modo que la lengua aquitana de la antigüedad ha sido considerada habitualmente como la fase antigua de la lengua vasca documentada a partir de la Edad Media. Esto se debe principalmente a que en el proceso comparativo se han primado las similitudes a las diferencias, que también existen. Relacionado con este problema está el asunto de las relaciones internas entre la variedad vascónica, la aquitana y el vasco histórico de época medieval y moderna. En los últimos años la investigación acerca de la reconstrucción del protovasco propone situar la fase lingüística ancestral común a todos los dialectos vascos históricos no en un periodo alejado y ligado a la división tribal prerromana, sino en un periodo entre la Antigüedad tardía y la alta Edad Media. En esta presentación de la documentación antigua vascónica y aquitana hemos resaltado los rasgos lingüísticos unitarios (p. ej. la alternancia de suf. -so / -se para la formación de nombres de varón / mujer, que documentamos tanto en Aquitania como en la Vasconia meridional), aunque existen también diferencias no solo entre las variedades vascónica y aquitana (en sus bases onomásticas, en su preferencia por la derivación o composición, en la presencia o ausencia de algunos cambios, etc.), sino también entre las fases antiguas y las medievales y modernas ( $C f$. Gorrochategui 2017; e. p.; Lakarra 2018).

\subsection{Problemas epigráficos}

Hemos citado previamente algunos rasgos epigráficos de la documentación, como el reparto entre textos paleohispánicos directos y material onomástico secundario trasmitido a través de epigrafía latina, con las características propias de cada uno de los tipos: diferente cronología y atestiguación geográ- 
fica, gran escasez y fragmentariedad de los textos. Podemos añadir ahora la naturaleza no repetitiva de los textos, que dificulta su comprensión; es decir, no hay una tipología repetida de textos, como las téseras de hospitalidad celtibéricas o los epitafios funerarios ibéricos, donde se puedan aislar fórmulas y secuencias repetitivas. Ni siquiera las leyendas monetales constituyen conjuntos homogéneos desde el punto de vista lingüístico (como lo son las celtibéricas con nombres en -kos y las ibéricas en -sken), aunque sí lo hacen desde el punto de vista iconográfico. Hay que señalar también ciertas particularidades gráficas atestiguadas en algunas leyendas monetales de la zona vascónica, a las que hemos hecho referencia anteriormente. Primeramente hay que resolver el valor fonético de uno de ellos (el signo $\mathrm{T}$ ) y luego intentar explicar el origen y relación que tienen con signos formalmente idénticos o semejantes usados en otras zonas epigráficas, en el marco de las investigaciones sobre las relaciones entre las distintas escrituras paleohispánicas (Ferrer y Moncunill 2019).

La onomástica aquitana y vascónica se documenta casi exclusivamente sobre epigrafía lapídea de dos tipos, funeraria y votiva, con excepción de algún documento singular como el bronce de Áscoli. Son de gran interés las láminas votivas argénteas halladas en el pecio de Hagenbach en el río Rin (Gorrochategui 2003), por tratarse de un conjunto coherente asignable probablemente a un santuario concreto, donde el material permite ciertos análisis sociolingüísticos. Hay que señalar que no se conocen nombres indígenas atestiguados en grafitos, seguramente por deficiencias debidas a la recolección y publicación de este tipo de material. De contar con material onomástico sobre instrumentum, como ocurre en otras zonas lingüísticas como la gala, se podrían hacer estudios comparativos sobre la frecuencia y tipología de la onomástica atestiguada en cada tipo epigráfico. 


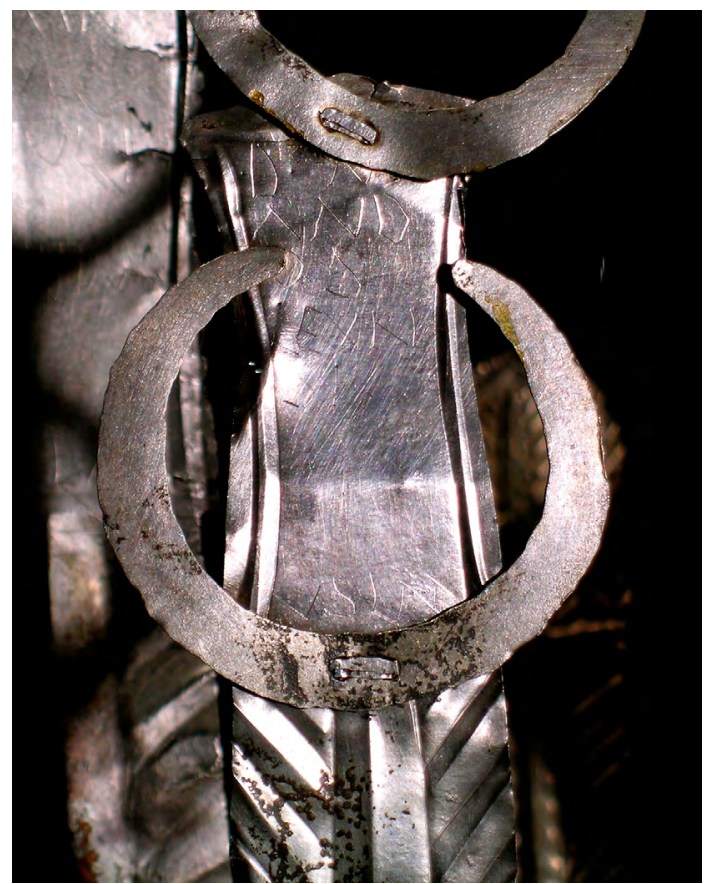

Fig. 4. Placa votiva de plata del tesoro de Hagenbach, Alemania ( $A E$ 1999, 1127-1160). Texto: $D$ (omino) M(arti) / And/os / Leuri/si / v(otum) s(olvit) l(ibens) $m$ (erito).

\subsection{Edición y publicación}

Los textos paleohispánicos de la zona han sido publicados separadamente a medida que fueron descubiertos, habiendo sido reunidos recientemente en el Banco de Datos Hesperia sobre Lenguas y Epigrafías Paleohispánicas. Como las áreas epigráficas mejor conocidas han sido tradicionalmente la ibérica y la celtibérica, Untermann incluyó los textos de la zona vascona tanto en una como en otra (zona E ibérica y K celtibérica de sus Monumenta Linguarum Hispanicarum). Hesperia, sin abandonar el reparto entre dichas grandes epigrafías, ha reunido estos textos bajo un epígrafe unitario, con referencia propia (zona I). Las leyendas monetales están recogidas y actualizadas en la Base Hesperia.

Solamente existen algunas pocas ediciones modernas de los corpora epigráficos latinos de las zonas en cuestión. Existe el proyecto de publicación de las inscripciones de Aquitania en la colección ILA (Inscriptions Latines d'Aquitaine), donde han sido editadas las inscripciones de algunas ciudades, como Auch, Dax, Tarbes, pero faltan todavía las correspondientes al riquísimo territorio de los Convenae y los Consorani. En el lado hispano, la segunda edición del $C I L$, en el fascículo dedicado al convento cesaraugustano, recogerá en breve las inscripciones latinas procedentes del territorio vascón. 


\section{$\begin{array}{llllllllllll}\mathbf{B} & \mathbf{I} & \mathbf{B} & \mathbf{L} & \mathbf{I} & \mathbf{O} & \mathbf{G} & \mathbf{R} & \mathbf{A} & \mathbf{F} & \mathbf{I} & \mathbf{A}\end{array}$}

Beltrán y Velaza 2009: F. Beltrán Lloris y J. Velaza, “De etnias y monedas: las «cecas vasconas», una revisión crítica”, en: J. Andreu Pintado (ed.), Los Vascones de las fuentes antiguas. En torno a una etnia de la Antigüedad peninsular, Barcelona 2009, 99-126.

Bernhard et al. 1990: H. Bernhard, H.-J. Engels, R. Engels y R. Petrovszky, Der römische Schatzfund von Hagenbach, Mainz 1990.

Bladé 1869: F.-J. Bladé, Études sur l'origine des Basques, París 1869.

Espinosa y Usero 1988: U. Espinosa y L. M. Usero, "Eine Hirtenkultur im Umbruch Untersuchungen zu einer Gruppe von Inschriften aus dem conventus Caesaraugustanus (Hispania Citerior)", Chiron 18, 1988, 477-504.

Estarán et al. 2015: M. J. Estarán, F. Beltrán, D. Balboa y V. Simón, Banco de Datos Hesperia de Lenguas Paleohispánicas (BDHESP). II. Numismática paleohispánica, Vitoria-Gasteiz 2015.

Ferrer et al. 2018: J. Ferrer, J. Velaza y O. Olesti, "Nuevas inscripciones rupestres latinas de Oceja y los IIIIviri ibéricos de Iulia Lybica”, DialHistAnc 44/1, 2018, 169-195 y 215-220.

Ferrery Moncunill 2019:J.Ferrery N. Moncunill, “Palaeohispanic writing systems. Classification, origin, and development”, en: A. G. Sinner y J. Velaza (eds.), Palaeohispanic Languages and Epigraphies, Oxford 2019, 78-108.

Gorrochategui 1984: J. Gorrochategui, Onomástica indígena de Aquitania, Bilbao 1984.

Gorrochategui 1987: J. Gorrochategui, "Situación lingüística de Navarra y aledaños en la antigüedad a partir de las fuentes epigráficas", en: Primer Congreso general de Historia de Navarra, 2, Pamplona 1987, 435-445.

Gorrochategui 2003: J. Gorrochategui, “Las placas votivas de plata de origen aquitano halladas en Hagenbach, Renania-Palatinado, Alemania", Revue Aquitania 19, 2003, 25-47.

Gorrochategui 2009: J. Gorrochategui, "Vasco antiguo: algunas cuestiones de geografía e historia lingüísticas”, PalHisp 9, Zaragoza 2009, 539-555.

Gorrochategui 2018: J. Gorrochategui, "La lengua vasca en la antigüedad”, en: J. Gorrochategui, I. Igartua, J.A. Lakarra (eds.), Historia de la Lengua Vasca, Vitoria-Gasteiz 2018, 245-305

Gorrochategui 2020: J. Gorrochategui, Aquitano y Vascónico, Zaragoza 2020.

Gorrochategui e. p.: J. Gorrochategui, "The relationship between Aquitanian and Basque: Achievements and challenges of the comparative method", en: Th. Chacon, N. Lee y W. Silva (eds.), Language Change, Descriptions and Documentation: Studies in Honour of Lyle Campbell, Edimburgo en prensa.

Hiriart et al. 2018: E. Hiriart, L. Callegarin, Ph. Gardes y F. Réchin, "La singularidad cultural del área pirenaico-occidental: dinámicas y persistencias entre la Edad del Hierro y la Época romana", ASJU 52/1-2, 2018, 323-343.

De Hoz 1995: J. de Hoz, "El poblamiento antiguo de los Pirineos desde el punto de vista lingüístico", en: J. Bertranpetit y E. Vives (eds.), Muntanyes i població. El passat dels Pirineus des d'una perspectiva multidisciplinària, Andorra la Vella 1995, 271-299. 
Joaquín Gorrochategui Churruca

Humboldt 1821: W. von Humboldt, Prüfung der Untersuchungen über die Urbewohner Hispaniens, Berlin 1821

ILA = Inscriptions Latines d'Aquitaine: J.-P. Bost, G. Fabre y L. Rodriguez, Landes et PyrénéesAtlantiques, Burdeos 2015; G. Fabre y J. Lapart, Auscii, Burdeos 2017; G. Fabre, Elusa/ Turba, Burdeos 2018.

Jullian 1908: C. Jullian, Histoire de la Gaule I, Paris 1908.

Katičić 1980: R. Katičić, “Die Balkanprovinzen”, en: G. Neumann y J. Untermann (eds.), Die Sprachen im römischen Reich der Kaiserzeit, Bonn 1980, 103-120.

Lakarra 2018: J.A. Lakarra, “La prehistoria de la lengua vasca”, en: J. Gorrochategui, I. Igartua y J.A. Lakarra (eds.), Historia de la Lengua Vasca, Vitoria-Gasteiz 2018, 23-244.

RIG: P.-Y. Lambert, Recueil des inscriptions gauloises, II.2: Textes gallo-latins sur instrumentum, Paris, 2002.

Luchaire 1876/7: A. Luchaire, “Les Origines linguistiques de l'Aquitaine”, Bul. Soc. Sciences, Lettres et Arts de Pau, 1876-1877, 349-423.

Luchaire 1879: A. Luchaire, Études sur les idiomes Pyrénéens de la région française, Paris 1879, [ed. facsim. Ginebra 1973]

Matasović 2019: R. Matasović, A Grammatical Sketch of Albanian for Students of IndoEuropean, Zagreb 2019.

Michelena 1954: L. Michelena, “De onomástica aquitana”, Pirineos 10, 1954, 409-458.

Mullen 2007: A. Mullen, "Evidence for Written Celtic from Roman Britain: A Linguistic Analysis of Tabellae Sulis 14 and 18", Studia Celtica 41 (2007), 31-45.

Orduña 2019: E. Orduña, “The Vasco-Iberian theory”, en A. G. Sinner y J. Velaza (eds.), Palaeohispanic Languages and Epigraphies, Oxford 2019, 219-239.

Ramírez Sádaba 1992: J. L. Ramírez Sádaba, "La onomástica de los vascones: autóctonos e inmigrantes”, Principe de Viana. Anejo, no 14, 1992 , 287-293.

Schmoll 1959: U. Schmoll, Die Sprachen der vorkeltischen Indogermanen Hispaniens und das Keltiberische, Wiesbaden 1959.

MLH: J. Untermann, Monumenta Linguarum Hispanicarum, Wiesbaden 1975-2000.

Urgell y Vallejo 2018: B. Urgell y J.M. Vallejo (eds.), Opera selecta Joaquín Gorrochategui I. Aquitanica /Akitaniera, Vitoria-Gasteiz 2018.

Vallejo 2016: J. M. Vallejo, Banco de Datos Hesperia de Lenguas Paleohispánicas (BDHESP). III. Onomástica paleohispánica, I. Antroponimia y teonimia 1. Testimonios epigráficos latinos, celtibéricos y lusitanos, y referencias literarias, Vitoria 2016.

Villar y Prósper 2005: F. Villar y B. Prósper, Vascos, celtas e indoeuropeos. Genes y lenguas, Salamanca 2005. 